\title{
Countermeasures and Suggestions on Pharmaceutical Production of Drugs in the Market of Cold Medicine based on Ali Health online drug sales platform 2019 big data
}

\author{
Wang Qian Ning ${ }^{1, \text { a }}$; Su Bo ${ }^{1, b,{ }^{*}}$;Zhang Lu ${ }^{1, \mathrm{c},}$, ;Wen $\mathrm{Ya}^{1}$;Jiang Xiao Rong ${ }^{1}$;Xue Yun $\mathrm{Jie}^{1}$;An Qi ${ }^{1}$ \\ ${ }^{1}$ School of Management, Hubei University of Traditional Chinese Medicine, Wuhan, China
}

\begin{abstract}
Starting from the basic situation of drug use when patients treat colds. It is found that the quantity of cold cold medicine and warm cold medicine in real life is not in accordance with the epidemiological statistics. There is the possibility of unreasonable production by supplier manufacturers. The purpose of this paper is to remind suppliers that the production of drugs should be carried out according to patients' disease conditions, so as to avoid misleading the market and thus affecting patients. From the two most important factors that affect the quantity of drugs - the supply and demand of drugs, the author makes statistics on the taste of drugs produced by manufacturers and the taste of drugs purchased by patients. It is found that the choice of cold medicine from both supply and demand is more than that of warm medicine, so it is very important for the education and guidance of manufacturers upstream of the value chain to reduce the mismatch between drug production and patient demand.
\end{abstract}

\section{Research Design}

\subsection{Data source}

Ali Health is the flagship platform in the big health field controlled by Alibaba Group, which carries out business such as pharmaceutical e-commerce, new retail, Internet medical and so on. Ali Health has an Internet drug sales license to purchase drugs online [1]. Ali health online drugstore contains more than 50,000 kinds of drugs. All of the data in this paper are from drugs classified as "flu drugs" in the main treatment of ali's health APP 2019 in october, and the data of the platform's october flu drugs have changed relative to the data for april, june and august of that year within 5 per cent, it was considered that the October data for that year could basically represent the annual monthly average. Since the data collection scope has been limited to the "cold medicine" treatment, the author only listed exclusion criteria.

\subsection{Drug exclusion criteria}

- Ali health APP found in the treatment of cold drugs which are not Chinese patent medicine will not be included. Example: Compound paracetamol amine tablets which formula is compound will not be included;

- When there are both Chinese medicinal materials and compounds in the drug prescription, if the main component of the drug prescription are Chinese medicinal materials, it will be counted, otherwise it will not be.Example: The compounds in the prescription of children's aminophenol amine granules are acetaminophen, gold-alkanamine hydrochloride, caffeine, chlorphenamine maleate, so the main components are compounds, it will not be included;

\subsection{Research technique}

\subsubsection{Drug input and literature review}

According to ali health online drugstore, the author entered the datum in the APP under the mall column of the cold medicine, including drug name, manufacturer, unit price, sales volume, prescription and its corresponding property. The prescription of the drug refers to the content of the drug classified as "component" in the packing box or instruction manual.The medicinal properties of traditional Chinese medicine were first found in the Shennong Herbal Classic, which refers to the various properties of drugs, including cold, heat, cool, even, efficacy and treatment [2]. At the same time, the author combs the articles about big data statistics in recent years, and establishes the cold medicine database for the purpose of statistics.

\subsubsection{Criteria for discrimination}

a) Interpretation and discrimination of property of medicinal herbs: The medicinal materials information included in the study were all based on the 2015 edition 
of the people's Republic of China [3]. At the same time, some drugs using modern processing technology, and there will be some changes in the processed materials, which should be determined according to the pharmacopoeia[4].If the processing technology just change the physical characteristics of drugs, the property of the drug has not changed, take its original medicinal property. Example: liquorice flow extract, according to the taste of liquorice input.

b) Identification of drug properties: The drug character is judged according to its prescription Chinese medicine[5]. After inquiring the medicinal properties of its prescription medicinal materials, we identified the properties according to the drug properties of the top $60 \%{ }^{1}$ of the medicinal materials ranked. First if the number of cold and cool medicinal materials in the first $60 \%$ of the drugs is more than that of warm and hot medicine, the medicine is cold and cool. Secondly, according to the drug instructions classified as "main treatment" column of the treatable disease symptoms to test if the results are reliable. Example: Ganmao Ling granule, the prescription are trigeminal bitter, calendula silver dish, wild chrysanthemum, gangmei, caffeine, the first $60 \%$ of the medicinal materials are trigeminal bitter, calendula silver dish and wild chrysanthemum, the property is bitter, cool and flat, so the drug preliminary judgment is cold nature. And then according to the description of Ganmao Ling granule, found that its main treatment symptoms are antipyretic Zhen pain, so the final judgment of cold Ling granule is cold medicine.

\subsubsection{Statistics and Methods}

This study on the cold medicine related to the property of drug prescription and the number of manufacturers statistics. By means of SPSS EXCEL2016 software, the author makes statistics on the connection between types, sales and taste of drugs. According to this big data, we preliminarily concluded that both manufacturers and patients had a preference on the property of the drugs.

\section{Statistical result And Analysis}

From the two most significant factors that affect the quantity of drug use, we will respectively statistics and analyze the result of the two factors. The final use of drugs, needs two stages, the first is produced, the second is needed, so the author started from the supply and demand. The supply side of cold medicine refers to the manufacturer of medicine, which constitutes the source of medicine, while the demand side of cold medicine refers to patients, which is the source of drug sales.

\subsection{Supply-side correlation}

Most ali health APP cold medicine are Chinese patent medicine, a number of medicine are in the same prescription but different names. In order to reduce the

\footnotetext{
1 The $60 \%$ standard is based on the previous experience in judging the cold and heat of drugs
}

situation that some manufacturers product "virtual lack substance" because of same prescription but different product names. The following analysis are based on the combination of different angles of the study of drug properties.

\subsubsection{Merger of Drug Agents and Points for Note}

For suppliers, in the cold proprietary Chinese medicine database, the drugs are classified by the prescription, the same prescription drugs are seemed as one kind of medicine, regardless of the dosage form, specification, unit price, etc., the name of the same prescription drugs are the name of the drug with the highest sales volume. Example: Lianhua Qingwen capsule and Lianhua Qingwen granule, although the dosage form is different, but the prescription are consistent, they are classified as the same kind of medicine, the former sales volume is larger than the latter one, so this kind of medicine is named as Lianhua Qingwen capsule. It should be distinguished that some drugs have similar names but different prescriptions. Ex: Jiawei Huoxiang Zhengqi Pill, Huoxue Xiang Zhengqi pills and Huoxiang Zhengqi water, although the names are similar, there are some differences in the prescriptions. Jiawei Huoxiang Zhengqi Pill is more than Huoxiang Zhengqi Pill with two herbs - big abdominal skin, ginger and jujube.The prescription of Huoxiang Zhengqi water are also different with the above two drugs.

\subsubsection{Drug formulation flavor}

According to the exclusion standard, Ali health platform entered a total of 856 Chinese patent medicines for colds, the 856 drugs classified by formula, after the classification, there are 184 Chinese patent medicines for colds. Among them ,150 cold prescriptions ,6 hot,16 warm, and 4 cool. The statistics are as follows:

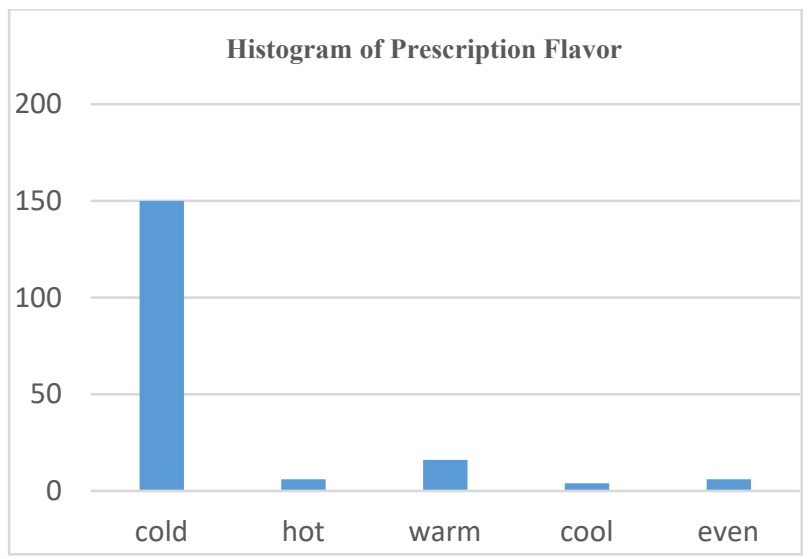

Figure 1.Histogram of Prescription Flavor

As the picture shows above, cold-type cold medicine group accounted for the largest proportion, accounting for $81.52 \%$. Secondly, the medicine of warm prescription are mainly patchouli qi water and prescription for cough, the main medicinal materials with high frequency are Angelica dahurica, Chen Pei, Chuanxiong and Poria cocos. 


\subsubsection{Production of drug types}

In the total of the 625 manufacturers, there are 184 kinds of drug groups. The largest was the Huoxiang Zhengqi water group, with 25 manufacturers. The second is Ganmao Qingre granule and Ganmao Ling granule, which are produced by 19 manufacturers.

The following is a statistical table showing the number of manufacturers in the group greater than or equal to 15 . There are 162 manufacturers, accounting for $25.9 \%$, while the number of the group only accounts for $4.35 \%$. There are two drugs in the table, namely Huoxiang Zhengqi Water and Huoxiang Zhengqi Pill, which are also the main sources of all the prescription of hot drugs. The reason may be that Huoxiang Zhengqi Water is the best and most widely used in the treatment of summer dampness cold.

TABLE I. NUMBER OF MANUFACTURERS $>=15$ CHINESE PATENT MEDICINES FOR COLDS

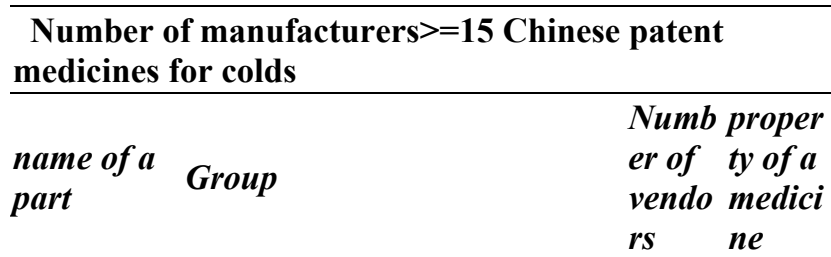

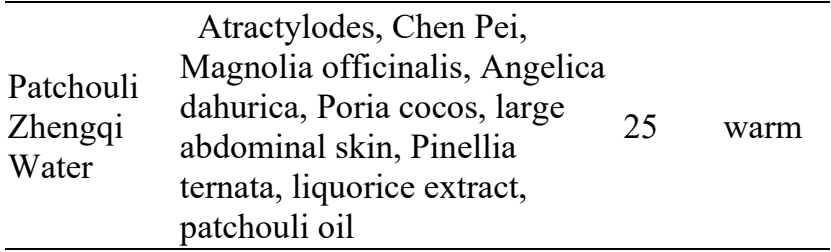

\begin{tabular}{|c|c|c|c|}
\hline $\begin{array}{l}\text { Cold } \\
\text { Qingre } \\
\text { granule }\end{array}$ & $\begin{array}{l}\text { Schizonepeta spike, } \\
\text { peppermint, Fangfeng, } \\
\text { Bupleurum, Perilla leaf, } \\
\text { Pueraria root, Platycodon } \\
\text { grandiflorum, bitter almond, } \\
\text { Angelica dahurica, bitter } \\
\text { ground, butadiene root }\end{array}$ & 19 & cold \\
\hline $\begin{array}{l}\text { Cold Ling } \\
\text { capsule }\end{array}$ & $\begin{array}{l}\text { Triple bitter, marigold silver } \\
\text { plate, wild chrysanthemum, } \\
\text { gangmei, caffeine }\end{array}$ & 19 & cold \\
\hline $\begin{array}{l}\text { shuanghuan } \\
\text { glian } \\
\text { mixture, } \\
\text { shuanghuan } \\
\text { glian } \\
\text { koufuye }\end{array}$ & $\begin{array}{l}\text { Honeysuckle, Scutellaria } \\
\text { baicalensis, Forsythia suspensa }\end{array}$ & 18 & cold \\
\hline $\begin{array}{l}\text { honeysuckl } \\
\text { e \& } \\
\text { forsythia } \\
\text { tablets }\end{array}$ & $\begin{array}{l}\text { Flos Lonicerae, Forsythia } \\
\text { Forsythia, Schizonepeta, } \\
\text { Douchi, Bamboo Leaves, } \\
\text { Arctium lappa, Root, } \\
\text { Platycodon grandiflorum, } \\
\text { Licorice }\end{array}$ & 17 & cold \\
\hline $\begin{array}{l}\text { banlangen } \\
\text { granules }\end{array}$ & isatis root & 16 & cold \\
\hline $\begin{array}{l}\text { Small } \\
\text { Bupleurum } \\
\text { granules }\end{array}$ & $\begin{array}{l}\text { Bupleurum, Scutellaria, } \\
\text { Pinellia ternata, Codonopsis, } \\
\text { Ginger, Licorice, Jujube }\end{array}$ & 16 & cold \\
\hline Children's & Platycodon,grandiflorum & 16 & even \\
\hline
\end{tabular}

cough

syrup

\subsection{Demand-side correlation}

To discuss the demand of patients with cold, we should first explain some unexpected increase of individual drug demand:

- Patient purchase error. Example: the patient wanted to buy cold Ling granule, accidentally bought into small Bupleurum granule;

- Patients' massive hoarding behavior. That is, the patient in a specific situation rather than depending on their own physical reasons for a large stock of certain drugs. Most of this behavior occurs in a certain period of disease flooding, with the characteristics of conformity, in a short period of time the sales of related drugs increasing faster. Example: In 2019, the new coronavirus led to a faster increase in the sales of Shuanghuanglian oral liquid, which had a preventive effect in a few days [6].

While the above two situations will distort real sales, they are less likely occur and will not be analysed here.

\subsubsection{Changes of drug flavor in different sales range}

This 899 kinds of Chinese patent medicines for colds, after grouped by sales volume, the drug properties of the drugs in different sales intervals are counted. As showed in the figure below, because the number of the drugs sold at 0 are so many, they are taken out separately for analysis, the number of drugs sold at 4000 and above are relatively small by contraries, so statistics are not repeated.

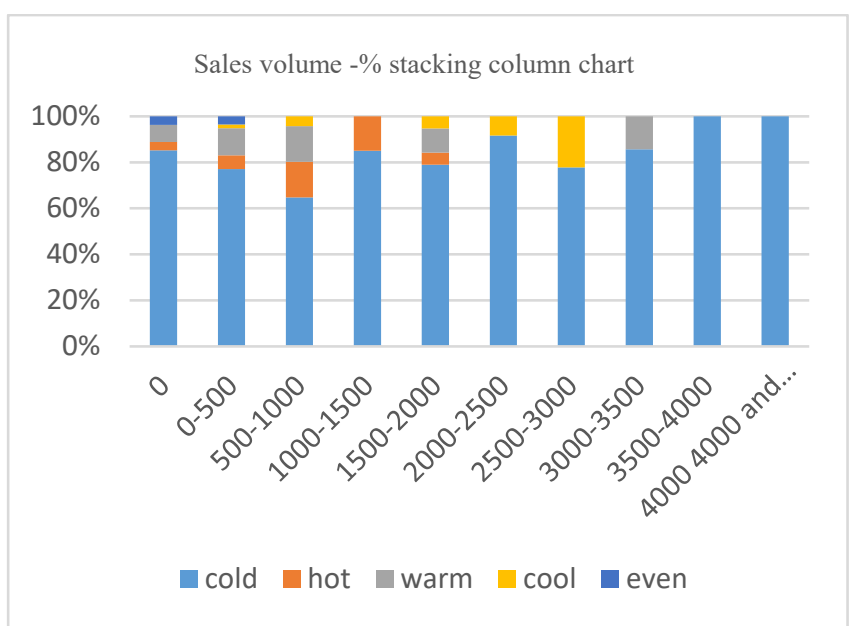

Figure 2.Sales volume -\% stacking column chart

- As can be seen from the picture above, the cold nature of the drugs occupy an absolute advantage, in sales of more than 2500 , up to $100 \%$ of the cold cold medicine situation.

- Drugs of warm nature are in the range of low sales volume, and the quantity of the drugs reaches the maximum value in the range of 
500-1000 of sales volume, as showed in the following figure.

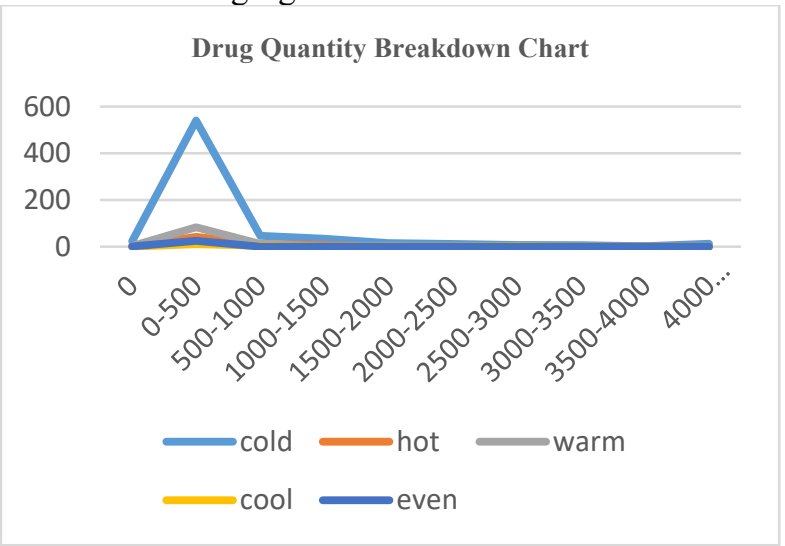

Figure 3.Drug Quantity Breakdown Chart

\subsubsection{Representing drug flavor}

For the demand side, the most representative drugs are those with higher sales. From the overall sales situation can be found that all the top sales of drugs - the cold Ling granules, Banlangen granules, and Kyoto Nianzian honey chain Chuanbei loquat ointment are cold. As the following table shows:

TABLE II. DRUG ANALYSIS AT THE TOP OF SALES

\begin{tabular}{|c|c|c|c|c|}
\hline \multicolumn{5}{|c|}{ Drug analysis at the top of sales } \\
\hline $\begin{array}{l}\text { name of } \\
\text { commodit } \\
y\end{array}$ & $\begin{array}{l}\text { Manufactu } \\
\text { rer }\end{array}$ & $\begin{array}{l}\text { medicinal } \\
\text { materials }\end{array}$ & $\begin{array}{l}\text { property } \\
\text { and } \\
\text { flavor }\end{array}$ & $\begin{array}{l}\text { Cold } \\
\text { or Hot } \\
\text { Drugs }\end{array}$ \\
\hline $\begin{array}{l}\text { Cold Ling } \\
\text { granule }\end{array}$ & $\begin{array}{l}\text { China } \\
\text { Resources } \\
39 \\
\text { Pharmaceut } \\
\text { ical Co., } \\
\text { Ltd. }\end{array}$ & $\begin{array}{l}\text { Triple bitter, } \\
\text { marigold silver } \\
\text { plate, wild } \\
\text { t chrysanthemu } \\
\text { m granite } \\
\text { plum, caffeine }\end{array}$ & \multicolumn{2}{|c|}{,even,cold cold } \\
\hline $\begin{array}{l}\text { banlangen } \\
\text { granules, } \\
\text { banlangen } \\
\text { keli }\end{array}$ & $\begin{array}{l}\text { Guangzhou } \\
\text { Baiyun } \\
\text { Mountain } \\
\text { Hutchison } \\
\text { Whampoa } \\
\text { Traditional } \\
\text { Chinese } \\
\text { Medicine } \\
\text { Co. Ltd. }\end{array}$ & isatis root & cold & cold \\
\hline $\begin{array}{l}\text { Pei pa koa } \\
\text { extract } \\
\text { from } \\
\text { nichian } \\
\text { honey } \\
\text { extract } \\
\text { from } \\
\text { Kyoto }\end{array}$ & $\begin{array}{l}\text { Kyoto } \\
\text { muncian } \\
\text { general } \\
\text { factory } \\
\text { co.Ltd. }\end{array}$ & $\begin{array}{l}\text { Fritillaria } \\
\text { chuanba, } \\
\text { Corydalis, } \\
\text { Corydalis, } \\
\text { Poria cocos, } \\
\text { orange red, } \\
\text { Platycodon } \\
\text { grandiflorum, } \\
\text { Pinellia } \\
\text { ternata, } \\
\text { Schisandra } \\
\text { chinensis, } \\
\text { Trichosanthes, }\end{array}$ & $\begin{array}{l}\text { Cold, } \\
\text { cold, } \\
\text { cool, } \\
\text { even,war } \\
\text { m, } \\
\text { even,war } \\
\text { m, } \\
\text { warm,col } \\
\text { d,warm, } \\
\text { warm, } \\
\text { warm, } \\
\text { warm,ev } \\
\text { en,warm }\end{array}$ & cold \\
\hline
\end{tabular}

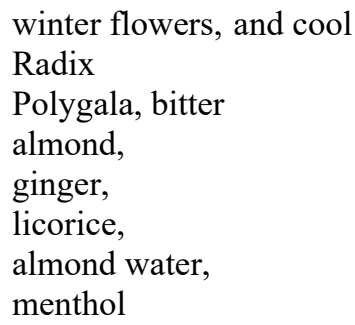

\subsection{Analysis of Research Results}

Both producers and demanders prefer cold medicine. The supply side of the cold nature of the group accounted for about $80 \%$, the patients' demand for drugs is also mainly cold nature medicine, as shown in figure 2. Most of the rest prescription of the medicine are damp-heat cold medicine, which is consistent with the patient's greater demand for treatment of damp-heat cold. Patients use more cold nature of cold medicine, next is cold medicine of treating damp-heat cold, rather than warm nature of cold medicine. It can be seen that the hot cold medicine has not really entered the patient's choice.

\section{Countermeasures and Suggestions for Pharmaceutical Production}

The probability of different types of colds varies from season to season. According to relevant epidemiological statistics, epidemic colds are more common at the end of spring, there are more wind heat cold in the summer, and more wind cold cold in autumn winter and early spring.

In ancient times, warm medicinal materials were used to treat colds. Query the ancient medical literature can be found that the ancient cold formula used in high frequency as drugs are mainly: licorice, Chen Pei, Chuanxiong and so on. And the proportion of warm, even and slightly warm medicinal materials used was the highest.

But according to the author's quantitative data statistical analysis, we can find that whether from the drug supply type of drug manufacturers, or from the patient's demand for drugs, the preference of cold drugs was greater than that of warm drugs. This is different from the statistics of related epidemiology and the use of traditional Chinese medicine for cold prescription. Therefore, it is very important for the management of the business direction of those manufacturers which can easily affect the needs of patients.

\subsection{Improved knowledge management skills and social responsibility for influenza drugs}

Chinese patent medicine is a kind of medicine which is processed from Chinese medicinal materials under the guidance of Chinese medicine theory. For the production decision of Chinese patent medicines, enterprises need to set up specific departments which with knowledge and capabilities of professional traditional Chinese medicine to guide. Improving the ability of knowledge management is helpful for enterprises to have a better understanding of the drugs produced, and then to 
produce the corresponding products according to the needs of patients. This will help manufacturers to produce the most suitable drugs for patients, and to be the enterprises which paying attention to the responsibility of restoring the health of patients.

\subsection{Enhance the vitality of enterprises by expanding their business scope}

Manufacturers can take advantage of the location upstream of the value chain to guide patients and implement the right development strategy. First of all, manufacturers can carry out patient education. Through the education of patients, they can drive the sales of manufactured drugs and change the traditional one-way communication direction of patients' market information to manufacturers. This can improve the welfare of the entire market, make the sales of products more targeted, and patients can get the drugs that are better for them. Second, manufacturers can expand the scope of services, increase corporate retail pharmacies, and train medical staff on TCM knowledge. on the other hand, it can reduce that warm cold medicine by the impact of the large market difficult to sell the risk, and finally can be obtained about the needs of patients, to further guide manufacturers to produce.

\subsection{Do comprehensive market research}

Through collecting official data, manufacturers understand the current status of the cold medicine market, drug circulation, existing problems, the prospects of the drug market, and propose reasonable policy recommendations based on the analysis results to solve the pain points of cold medicine. The market provides guidance and basis for the production and operation of cold medicines, which is conducive to protecting people's lives. In addition to collecting data on patient needs, it is more important to study the characteristics of modern epidemiology, geographical location, the relationship between disease evolution and disease type.

Collating relevant data and making predictions in order to adjust the structure of the products.

\section{Acknowledgment}

Hubei province education plan 2019 key topic: local university economic management undergraduate talent training mode innovation research ,2019 GA029.

\section{References}

1. Xu Fei. Ali Health, Global Drug Alliance Online [J].] Computers and Networks ,2017,43(18):37.

2. Liu Yue. A Study on the Evolution of Pharmacological Theory of the Origin of Pharmacology and "Four Qi "[ D].] Chinese Academy of Traditional Chinese Medicine ,2011.

3. ed by the National Pharmacopoeia Commission. Chinese Pharmacopoeia 2015 Edition [M].] Beijing: China Medical Science and Technology Press ,2015.

4. Lingyun Zhong, Meina Cui, Ming Yang, Qianfeng Gong. A Modern Study on Processing Influencing Drug Properties of Traditional Chinese Medicine [J].] Chinese Journal of Traditional Chinese Medicine ,2019,44(23):5109-5113.

5. Liu Jinlian, Zhang Rui, Liu Yebin, Hou Yan, Wang Linyuan, Wang Chun, Zhang Jianjun, Gao Xuemin. A Study on the Literature of Norrie and the Theory of Traditional Chinese Medicine [J].] Chinese Journal of Traditional Chinese Medicine ,2020,45(05):984-990.

6. Xia Chin. From Radix Isatidis to Shuanghuanglian [J].] Trade Union Expo ,2020(05):38. 